\title{
Implementation of the lighting control algorithms in the KNX system
}

\author{
Stawomir Sowa ${ }^{1, *}$, Jarosław Gielniak ${ }^{1}$ \\ ${ }^{1}$ Institute of Electric Power Engineering, Faculty of Electrical Engineering Poznan University of Technology, Poland
}

\begin{abstract}
There are many different ways of managing the lighting. The usage of appropriately selected controlling algorithms allows to increase the functionality, improve the comfort of using and introduces measurable benefits in the form of power consumption savings. In order to precisely apply the proper lighting control algorithms, it is important to know the distribution of light intensity in the room. This article is aimed at comparing different ways of lighting control and contains a control idea based on the KNX system, which is a popular building automation system. It is very useful for the implementation of lighting control criteria.
\end{abstract}

\section{Introduction}

Lighting is an important part of our lives. It affects the comfort of being in a room, the quality and work safety as well as our well-being. The need to maintain appropriate lighting parameters has been recognised in the legislative provisions. The possibility of ensuring the required parameters of lighting in rooms is possible because of the application of appropriate lighting control, which will ensure the required intensity of light throughout the room area. This may be achieved by controlling the lighting system by using algorithms that use information about the light distribution inside the room. The paper presents the application of algorithms controlling lighting in the room based on the information concerning the illuminance research and done with the use of KNX system.

\subsection{Lighting regulations}

\subsubsection{European norms and standards}

One of the guidelines is CEN/TC $169 \mathrm{~N} 0618$ [1]. It defines the methods for assessing the availability of light and prescribes the conditions necessary to ensure a minimum level of light in the rooms. Since 2003, all EU members have adopted the common standard EN-124641 for workplace lighting requirements [2].

\subsubsection{Legislation and regulations in Poland.}

In Poland, the PN-EN 12464 [2] is used in the first place, and it is mandatory in all EU Member countries. It defines the values of light intensity and also defines a number of terms related to light in the interiors. In September 2017, a new version of the 15193 standard [3] was released. In this new version, the impact of daylight availability and control on energy efficiency was determined much more precisely than in previous versions.

\subsection{Lighting control systems}

This article examines only the automatic way of control, which can be implemented in three ways:

- switch on/off

- darken/lighten

- darken/lighten with daylight control.

The choice of an appropriate control method depends on the function of the room, its technical parameters and the location in the building. The first type of control will be limited only to switching on the entire lighting when the daylight intensity does not ensure the desired parameters of the room lighting. However, if the daylight intensity is satisfactory, the controls will switch off the lighting in the entire room. A more advanced, but also more effective way, is to control the darken/lighten type. It regulates the power of lighting fixtures topically so as to provide the required illumination on the reference surface and it is necessary to darken when the artificial lighting is at a lover value.

The third way of control, the most energetically and economically effective, is to use light intensity sensors, that will measure the light intensity values inside and outside the building. The results of the light distribution measurements have been presented in Figure 1 and are useful for assessing the savings in electricity consumption for lighting. Calculations prove that it is possible to achieve savings of up to $52 \%$ compared to energy consumption without lighting control [4].The method of implementation of all control versions in the $\mathrm{KNX}$ system is presented in point 3 of this article. 
Table 1 The intensity of the light inside the room and the operating status of the light fixture.

\begin{tabular}{|c|c|c|c|}
\hline $\begin{array}{c}\text { Light intensity } \\
\text { E [lux] }\end{array}$ & $\begin{array}{c}\text { luminairies } \\
\text { Row I }\end{array}$ & $\begin{array}{c}\text { luminairies } \\
\text { Row II }\end{array}$ & $\begin{array}{c}\text { luminairies } \\
\text { Row III }\end{array}$ \\
\hline$<1200$ & ON & ON & ON \\
\hline $1200-2100$ & OFF & ON & ON \\
\hline $2100-3200$ & OFF & OFF & ON \\
\hline$>3200$ & OFF & OFF & OFF \\
\hline
\end{tabular}

\section{Light intensity inside the room}

The light intensity of the room shall be maintained over its entire area. Naturally, by moving away from the window, the light intensity decreases. If the required light intensity is not provided in a particular room width, suitable luminaires with artificial lighting must be provided. The energy efficiency of an object can be improved significantly when artificial lighting is used. The lighting control shall be so designed that where the required intensity is provided, no additional artificial lighting shall be supplied. The study of such a distribution of light intensity allowed to develop appropriate criteria of regulation of light intensity.

\subsection{The measurement of the light distribution}

The studies were carried out over a period of 18 months, which made it possible to perform them in all seasons in various weather conditions. The diagrams of the light distribution in the rooms are shown in Fig. 2.

Measurements of the light distribution in the room show that the course of the light distribution curves is very similar for different weather conditions.

The research has also proved that the location of the room in relation to the parts of the world does not have a significant impact on the distribution of the light intensity [5].

\subsection{Test results}

The measurements of the light distribution in the room show that the course of the light distribution curves is very similar for different weather conditions. The research has also shown that the location of the room in relation to the parts of the world does not have any significant impact on the distribution of the light intensity [4].

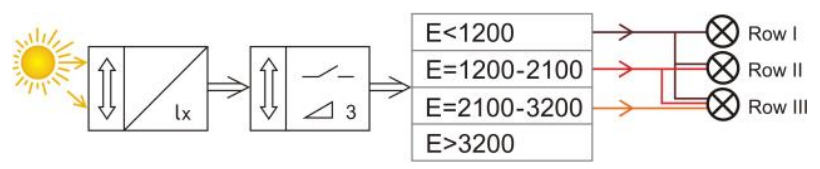

Fig. 1. An overview diagram of the lighting control in KNX system.

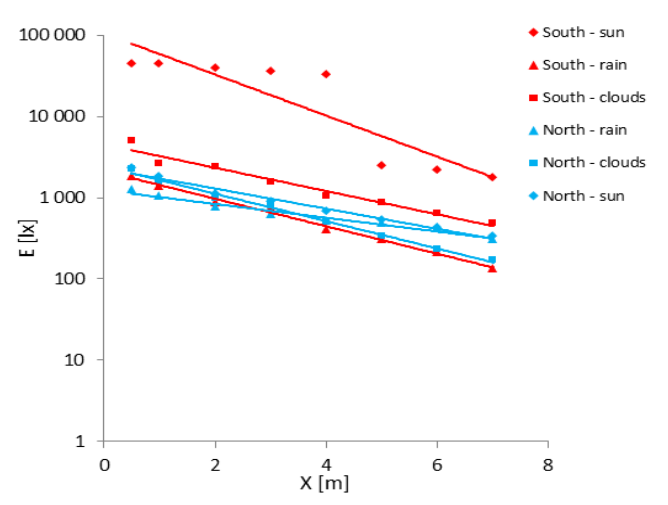

Fig. 2. Light distribution in the room from $\mathrm{N}$ and $\mathrm{S}$ for different weather conditions.

\subsection{Test results and its usage}

The obtained results of research into the distribution of light intensity in the room, allowed to develop algorithms for controlling artificial lighting in such a way as to ensure, as far as possible, uniform lighting intensity over the entire room. At the same time, an economic effect was achieved in the form of savings in energy consumption for lighting. The threshold values for the daylight intensity measured at the window inside the room are shown in table 1 and are directly related to the switching on and off of the respective lighting system rows in the room.

\section{Controlling in the KNX system}

Lighting control can be achieved with one of the many available building automation control systems. The KNX system is becoming increasingly popular and well known among hardware manufacturers and installers. Control in this standard will consist in switching on/off dimming and lightening the respective rows of light fixture. The algorithm is shown in Figure 1.

\section{References}

1. PrEN 15193: Energy performance of buildings Energy requirements for lighting (2006)

2. PN-EN 12464-1:2012 Light and lighting - lighting at the workplaces - Part 1: Indoor workplace (2012)

3. PN-EN 15193:2017E Energy performance of buildings - Energy requirements for lighting (2017)

4. S. Sowa, A. Kamińska, Prz. Elektrotech. 2, 193-197 (2018)

5. S. Sowa, Informatyka Automatyka Pomiary w Gospodarce i Ochronie Środowiska 3, 78-81 (2017)

6. S. Sowa, J. Gielniak, Pozn. Univ. Technol. Acad. J. Electr. Eng. 96, 153-162 (2018) 